Original Article

\title{
Decrease in Talocrural Joint Mobility is Related to Alteration of the Arterial Blood Flow Velocity in the Lower Limb in Diabetic Women
}

\author{
Elaine Caldeira de Oliveira Guirro, PT, PhD ${ }^{1)^{*}}$, Rinaldo Roberto de Jesus Guirro, PT, PhD ${ }^{1)}$, \\ Almir Vieira Dibai-Filho, PT $^{1)}$, Thais Montezuma, PT $^{1)}$, \\ Maíta Mara de Oliveira Lima Leite Vaz, PT ${ }^{1)}$ \\ 1) Department of Biomechanics, Medicine and Rehabilitation of the Locomotor Apparatus, Medical \\ School of Ribeirão Preto, University of São Paulo: Avenida dos Bandeirantes, 3900, Monte Alegre, \\ Ribeirão Preto, SP, Brazil
}

\begin{abstract}
Purpose] The purpose of this study was to correlate the talocrural range of motion (ROM) and blood flow velocity in the lower limb arteries of diabetic women. [Subjects and Methods] Thirty women were divided into a control group (G1), consisting of 15 sedentary right-handed subjects (41.27 \pm 7.24 years old) who had no history of blood system disorder, and a diabetes group (G2), consisting of 15 sedentary right-handed subjects (57.87 \pm 6.20 years old) who had type 2 diabetes mellitus. Talocrural ROM was measured by using goniometry for dorsiflexion and plantar flexion movements. In addition, blood flow velocity of the dorsalis pedis, posterior tibial, and popliteal arteries was also assessed. [Results] No significant differences were found between the groups by comparing talocrural ROM and arterial blood velocity. However, a significant association was found in G2 only between the following variables: plantar flexion and blood flow velocity of the dorsalis pedis artery $(\mathrm{rs}=0.57)$, plantar flexion and blood flow velocity of the popliteal artery $(\mathrm{rs}=0.50)$, and dorsiflexion and blood flow velocity of the posterior tibial artery $(\mathrm{rs}=0.57)$. [Conclusion] The decrease in talocrural ROM is related to a decrease in the arterial blood flow velocity in diabetic women.

Key words: Diabetes mellitus, Arthrometry, Physical therapy
\end{abstract}

(This article was submitted Sep. 10, 2013, and was accepted Nov. 4, 2013)

\section{INTRODUCTION}

Diabetes is a systemic pathological condition that has implications for the locomotor system, which may affect muscle functioning ${ }^{1)}$, joint structures ${ }^{2,3)}$, postural control ${ }^{4)}$, and peripheral nerve integrity ${ }^{5}$. In this sense, the physiotherapist plays a key role in the rehabilitation of these patients, as knowing the changes in physiological mechanisms and their functional repercussions is an important factor for a successful therapy ${ }^{6,7)}$.

In this context, the flexibility within the ranges of joint integrity is a key condition for locomotor system functioning. Due to diabetes, one can observe reductions in joint mobility resulting from the process of nonenzymatic glycosylation of collagen, which increases the number of crosslinkages. Therefore, there is a greater accumulation of these cross-linkages in the extracellular matrix of the joint capsule, ligaments, tendons, and muscles, thus altering the mechanical properties of these tissues and reducing their elas-

*Corresponding author: Elaine Caldeira de Oliveira Guirro (E-mail: ecguirro@fmrp.usp.br)

(C2014 The Society of Physical Therapy Science. Published by IPEC Inc. This is an open-access article distributed under the terms of the Creative Commons Attribution Non-Commercial No Derivatives (by-ncnd) License $<$ http://creativecommons.org/licenses/by-nc-nd/3.0/> . ticity and resistance to traction and increasing mechanical rigidity ${ }^{2,3,8)}$. In addition, it should also be emphasized that the ankle is one of the joints most affected by diabetes ${ }^{8)}$.

Another important measurement of corporal function is the peripheral arterial blood flow. One can observe that diabetic individuals are at a higher risk of developing occlusive vascular diseases as a result of the close relationship between diabetes and the process of atherogenesis. Therefore, hyperglycemia has several harmful repercussions on the vascular endothelium depending on the changes in the levels of nitric oxide, angiotensin II, prostacyclin, endothelin-1, plasminogen activator inhibitor-1, and others compounds ${ }^{9,10)}$. Although most of the cases with changes in peripheral arterial flow occur asymptomatically, decreased blood flow has clinical implications such as presence of pain, ischemia, and metabolic failure ${ }^{11)}$.

In view of the above and considering both blood flow and joint flexibility as two important components for performance of locomotor functions, the objective of the present study was to correlate the talocrural range of motion (ROM) and blood flow velocity in the lower limb arteries of diabetic women. Therefore, our hypothesis is that there is an association between the variables under study. 


\section{SUBJECTS AND METHODS}

The procedures in the present study were approved by the Ethics Research Committee of the Methodist University of Piracicaba (protocol number 105/04). All the volunteers confirmed their participation in the study by signing an informed consent form.

This was controlled cross-sectional study in which one physiotherapist performed the initial screening, a second one evaluated the talocrural ROM, a third one measured the blood flow velocity, and finally one researcher performed data and statistical analyses.

Thirty women were consecutively recruited from the communities of the city of Piracicaba (SP, Brazil) by means of verbal invitation, all being divided into two groups as follows: a control group (G1), consisting of 15 sedentary righthanded women with a mean age of $41.27 \pm 7.24$ years and no history of blood system disorder, and a diabetes group (G2), consisting of 15 sedentary right-handed women with a mean age of $57.87 \pm 6.20$ years and type 2 diabetes mellitus.

The exclusion criteria adopted for groups G1 and G2 were previous history of ankle lesion and regular practice of physical activities. Also, those volunteers presenting other circulation or orthopaedic-related disorders were excluded from $\mathrm{G} 2$.

Considering the eligibility criteria mentioned above, there was no sample loss in the present study.

The patients evaluated had diabetes for $7.50 \pm 1.20$ years, controlled by oral hypoglycemic agents, and presented mild or moderate peripheral arterial disease according to the ankle/brachial index.

Initially, in order to match the volunteers with the eligibility criteria, a questionnaire on personal data, daily habits, and previous family and disease history was applied. In addition, their lower limbs were evaluated by inspection and palpation.

Next, the arterial blood flow in the lower limbs was evaluated. To do, a portable Doppler device operating with continuous waves of 4 and $8 \mathrm{MHz}$ was used for spectral analysis (VersaLab SE, Natus Medical Incorporated, San Carlos, CA, USA), thus allowing data on blood flow components such as velocity and direction to be measured and recorded in detail.

The volunteers were examined after a 10 -minute rest period in the supine position. Data on the right lower limb were collected for the following sites: back of the foot, posterior region to the medial malleolus, and popliteal region with back of the foot positioned at 30 degrees in order to intensify the sound wave, thus forming a 45 degree angle in relation to the horizontal plane. Doppler signals were captured in the dorsalis pedis and posterior tibial arteries with an $8 \mathrm{MHz}$ probe and in the popliteal artery with a $4 \mathrm{MHz}$ probe, with the maximum blood flow velocity being used as a parameter. Three measurements were performed for each artery, and the mean value was used for statistic calculation.

Assessment of talocrural ROM was performed by a trained physiotherapist, who used a universal goniometer (CARCI, São Paulo, SP, Brazil). The volunteers remained in the dorsal decubitus position with a support beneath the knees in order to avoid full extension of them. The goniometer's fixed arm was positioned at the lateral face of the fibula, whereas the movable arm was placed at the lateral face of the foot and the axis was placed at the ankle joint along with the lateral malleolus ${ }^{12)}$. In this way, the maximum plantar flexion and dorsiflexion movements could be always measured from a neutral position. For each movement, three measurements were performed, and the mean value was used for statistic calculation ${ }^{13)}$.

The Shapiro-Wilk test was used to assess data normality, whereas the Mann-Whitney test was used for comparison between groups. The associations between the variables were assessed by using the Spearman's correlation coefficient. Interpretation of the correlation coefficients was based on Munro's classification as follows: low, between 0.26 and 0.49 ; moderate, between 0.50 and 0.69 ; high, between 0.70 and 0.89 ; and very high, between 0.90 and $1.00^{14)}$. A significance level of $5 \%$ was considered for all statistical analyses. Data analysis was performed by using the BioEstat software, version 5.3 (Belém, PA, Brazil).

\section{RESULTS}

Tables 1 and 2 show the correlations between talocrural ROM and arterial blood flow in women from the control and diabetes groups, respectively. In G2, a significant, moderate and positive association was found between plantar flexion movement and blood flow in the dorsalis pedis ( $\mathrm{rs}=0.57, \mathrm{p}$ $=0.02)$ and popliteal $(\mathrm{rs}=0.50, \mathrm{p}=0.04)$ arteries as well as between dorsiflexion movement and the popliteal artery (rs $=0.57, \mathrm{p}=0.02$ ).

Tables 3 and 4 show the comparisons between groups regarding the talocrural ROM and blood flow velocity, respectively. No significant differences were found $(p>0.05)$.

\section{DISCUSSION}

In the present study, a positive correlation between arterial blood flow velocity and ankle joint flexibility was observed in diabetic individuals. Considering the harmful effects of diabetes on several tissues of the human body, one can emphasize the nonenzymatic glycosylation of collagen and its negative consequences with respect to joint flexibility as a possible physiopathological explanation for the findings reported in the present study ${ }^{2,3,8)}$. Therefore, decreased ankle joint mobility in diabetic individuals brings a biomechanical disadvantage, with reduction in the effectiveness of the function of the sural triceps muscle pump, which has negative repercussions on the peripheral vascular system $^{15-17)}$.

Besides the above-mentioned clinical aspects, there is an increased risk of atherogenesis with consequent reduction in vascular diameter due to the presence of chronic hyperglycemia, insulin resistance, and dyslipidemia ${ }^{18)}$. Complementarily, a study conducted by Ravikumar et al. ${ }^{19)}$ investigated the structural aspects of the arteries in diabetic individuals, such as the increase in arterial rigidity and impairment of endothelial function compared with a control group.

Additionally, diabetes also has negative repercussions on the musculoskeletal system. Within this context and 
Table 1. Association between the talocrural range of motion (degrees) and maximum blood flow velocity $(\mathrm{cm} / \mathrm{s})$ in the arteries of the lower limb of the control group (G1)

\begin{tabular}{lc}
\hline Correlation & rs \\
\hline Plantar flexion $\times$ dorsalis pedis artery & 0.08 \\
Plantar flexion $\times$ posterior tibial artery & 0.49 \\
Plantar flexion $\times$ popliteal artery & 0.04 \\
Dorsiflexion $\times$ dorsalis pedis artery & 0.08 \\
Dorsiflexion $\times$ posterior tibial artery & 0.21 \\
Dorsiflexion $\times$ popliteal artery & 0.16 \\
\hline
\end{tabular}

No statistical significance $(\mathrm{p}>0.05$, Spearman's correlation coefficient)

Table 3. Comparison of the talocrural range of motion (ROM) between the control (G1) and diabetes (G2) groups

\begin{tabular}{lcc}
\hline Talocrural ROM & G1 & G2 \\
\hline Plantar flexion (degrees) & $36.07 \pm 17.77$ & $30.20 \pm 9.55$ \\
Dorsiflexion (degrees) & $14.93 \pm 4.71$ & $12.47 \pm 5.95$ \\
\hline No significant differences $(\mathrm{p}>0.05$, Mann-Whitney test)
\end{tabular}

considering the aging process, Leenders et al. ${ }^{1)}$ noted that diabetic individuals have a decline in leg lean mass, muscle strength, and functional capacity compared with normoglycemic controls. Kalyani et al. ${ }^{20)}$ also reported that older adults with diabetes have lower quadriceps strength resulting from the presence of comorbidities and walk slower than those without diabetes.

Based on the results found in the present study, one can highlight clinical implications such as the importance of considering ankle joint mobility as a key factor not only for locomotor function, as reported by Pandy and Andriacchi $^{21)}$, Kleipool and Blankevoort ${ }^{22)}$, and Vandervoort ${ }^{23)}$, but also for good functioning of the peripheral vascular system ${ }^{15)}$. Looking at the previous literature, it can be seen that clinical trials have been performed with diabetic patients having peripheral vascular disease whose rehabilitation was based on ankle exercises ${ }^{24-26)}$.

With regard to the values of the talocrural ROM, Marques $^{12)}$ established dorsiflexion excursion of 0 to $20^{\circ}$ and plantar flexion excursion of 0 to $45^{\circ}$ as standards of normality in the population. Thus, in the present study, it was observed that the average values of dorsiflexion and plantar flexion in the diabetes group were reduced by approximately 38 and $33 \%$, respectively, when considering the above normality values. However, despite this reduction, there was no significant difference when compared with control women.

With regard to the limitations of the present study, one can emphasize the lack of investigation of the presence of peripheral arterial disease in the volunteers and the use of convenience sampling. In addition, because strength and electric activity of lower limb muscles were not considered in the present study, it is suggested that further studies should be carried out to assess muscle behavior in relation
Table 2. Association between the talocrural range of motion (degrees) and maximum blood flow velocity $(\mathrm{cm} / \mathrm{s})$ in the arteries of the lower limb of the diabetes group (G2)

\begin{tabular}{ll}
\hline Correlation & rs \\
\hline Plantar flexion $\times$ dorsalis pedis artery & $0.57^{*}$ \\
Plantar flexion $\times$ posterior tibial artery & 0.30 \\
Plantar flexion $\times$ popliteal artery & $0.50^{*}$ \\
Dorsiflexion $\times$ dorsalis pedis artery & 0.29 \\
Dorsiflexion $\times$ posterior tibial artery & $0.57^{*}$ \\
Dorsiflexion $\times$ popliteal artery & 0.06 \\
\hline
\end{tabular}

*Statistically significant $(\mathrm{p}<0.05$, Spearman's correlation coefficient)

Table 4. Comparison of maximum blood flow velocity between the control (G1) and diabetes (G2) groups

\begin{tabular}{lcc}
\hline Artery & G1 & G2 \\
\hline Dorsalis pedis $(\mathrm{cm} / \mathrm{s})$ & $26.11 \pm 11.71$ & $26.51 \pm 14.55$ \\
Posterior tibial $(\mathrm{cm} / \mathrm{s})$ & $55.47 \pm 13.06$ & $40.91 \pm 12.24$ \\
Popliteal $(\mathrm{cm} / \mathrm{s})$ & $34.13 \pm 6.59$ & $41.00 \pm 18.78$ \\
\hline \multicolumn{2}{l}{ No significant differences $(\mathrm{p}>0.05$, Mann-Whitney test) }
\end{tabular}

to both blood flow and joint flexibility and to correlate them. We also emphasize the importance of future interventional clinical investigations that consider the results of the present study.

In conclusion, considering the experimental conditions of the present study, the data showed that impairment of talocrural ROM is related to a decrease in arterial blood flow velocity in diabetic women.

\section{REFERENCES}

1) Leenders M, Verdijk LB, van der Hoeven L, et al.: Patients with type 2 diabetes show a greater decline in muscle mass, muscle strength, and functional capacity with aging. J Am Med Dir Assoc, 2013, 14: 585-592. [Medline] [CrossRef]

2) Giacomozzi C, D'Ambrogi E, Cesinaro S, et al.: Muscle performance and ankle joint mobility in long-term patients with diabetes. BMC Musculoskelet Disord, 2008, 9: 99. [Medline] [CrossRef]

3) García-Álvarez Y, Lázaro-Martínez JL, García-Morales E, et al.: Morphofunctional characteristics of the foot in patients with diabetes mellitus and diabetic neuropathy. Diabetes Metab Syndr, 2013, 7: 78-82. [Medline] [CrossRef]

4) Vaz MM, Costa GC, Reis JG, et al.: Postural control and functional strength in patients with type 2 diabetes mellitus with and without peripheral neuropathy. Arch Phys Med Rehabil, 2013, 94: 2465-2470. [Medline] [CrossRef]

5) Sytze Van Dam P, Cotter MA, Bravenboer B, et al.: Pathogenesis of diabetic neuropathy: focus on neurovascular mechanisms. Eur J Pharmacol, 2013, 719: 180-186. [Medline] [CrossRef]

6) Taylor JD, Fletcher JP, Tiarks J: Impact of physical therapist-directed exercise counseling combined with fitness center-based exercise training on muscular strength and exercise capacity in people with type 2 diabetes: a randomized clinical trial. Phys Ther, 2009, 89: 884-892. [Medline] [CrossRef]

7) Stein C, Eibel B, Sbruzzi G, et al.: Electrical stimulation and electromagnetic field use in patients with diabetic neuropathy: systematic review and meta-analysis. Braz J Phys Ther, 2013, 17: 93-104. [Medline]

8) Abate M, Schiavone C, Pelotti P, et al.: Limited joint mobility (LJM) in elderly subjects with type II diabetes mellitus. Arch Gerontol Geriatr, 2011, 53: 135-140. [Medline] [CrossRef]

9) Garcia LA: Epidemiology and pathophysiology of lower extremity periph- 
eral arterial disease. J Endovasc Ther, 2006, 13: II3-II9. [Medline] [CrossRef]

10) Shammas NW: Epidemiology, classification, and modifiable risk factors of peripheral arterial disease. Vasc Health Risk Manag, 2007, 3: 229-234. [Medline] [CrossRef]

11) Federman DG, Kravetz JD: Peripheral arterial disease: diagnosis, treatment, and systemic implications. Clin Dermatol, 2007, 25: 93-100. [Medline] [CrossRef]

12) Marques AP: Manual de goniometria, 2nd ed. Barueri: Manole, 2003

13) Pertille A, Macedo AB, Dibai Filho AV, et al.: Immediate effects of bilateral grade III mobilization of the talocrural joint on the balance of elderly women. J Manipulative Physiol Ther, 2012, 35: 549-555. [Medline] [CrossRef]

14) Munro BH: Correlation. In: Munro BH. Statistical methods for health care research, 4th ed. Philadelphia: Lippincott, 2001, pp 223-243.

15) Dix FP, Brooke R, McCollum CN: Venous disease is associated with an impaired range of ankle movement. Eur J Vasc Endovasc Surg, 2003, 25: 556-561. [Medline] [CrossRef]

16) Padberg FT Jr, Johnston MV, Sisto SA: Structured exercise improves calf muscle pump function in chronic venous insufficiency: a randomized trial. J Vasc Surg, 2004, 39: 79-87. [Medline] [CrossRef]

17) Panny M, Ammer K, Kundi M, et al.: Severity of chronic venous disorders and its relationship to the calf muscle pump. Vasa, 2009, 38: 171-176. [Medline] [CrossRef]

18) Jude EB, Eleftheriadou I, Tentolouris N: Peripheral arterial disease in diabetes - a review. Diabet Med, 2010, 27: 4-14. [Medline] [CrossRef]

19) Ravikumar R, Deepa R, Shanthirani C, et al.: Comparison of carotid intima-media thickness, arterial stiffness, and brachial artery flow mediated dilatation in diabetic and nondiabetic subjects (The Chennai Urban Population Study [CUPS-9]). Am J Cardiol, 2002, 90: 702-707. [Medline] [CrossRef]

20) Kalyani RR, Tra Y, Yeh HC, et al.: Quadriceps strength, quadriceps power, and gait speed in older U.S. adults with diabetes mellitus: results from the National Health and Nutrition Examination Survey, 1999-2002. J Am Geriatr Soc, 2013, 61: 769-775. [Medline] [CrossRef]

21) Pandy MG, Andriacchi TP: Muscle and joint function in human locomotion. Annu Rev Biomed Eng, 2010, 12: 401-433. [Medline] [CrossRef]

22) Kleipool RP, Blankevoort L: The relation between geometry and function of the ankle joint complex: a biomechanical review. Knee Surg Sports Traumatol Arthrosc, 2010, 18: 618-627. [Medline] [CrossRef]

23) Vandervoort AA: Ankle mobility and postural stability. Physiother Theory Pract, 1999, 15: 91-103. [CrossRef]

24) Cousin A, Popielarz S, Wieczorek V, et al.: Impact of a rehabilitation program on muscular strength and endurance in peripheral arterial occlusive disease patients. Ann Phys Rehabil Med, 2011, 54: 429-442. [Medline] [CrossRef]

25) Tebbutt N, Robinson L, Todhunter J, et al.: A plantar flexion device exercise programme for patients with peripheral arterial disease: a randomised prospective feasibility study. Physiotherapy, 2011, 97: 244-249. [Medline] [CrossRef]

26) Castro-Sánchez AM, Matarán-Peñarrocha GA, Feriche-Fernández-Castanys $B$, et al.: A program of 3 physical therapy modalities improves peripheral arterial disease in diabetes type 2 patients: a randomized controlled trial. J Cardiovasc Nurs, 2013, 28: 74-82. [Medline] [CrossRef] 